\title{
DIGITAL DESIGN AND ROBOTIC PRODUCTION OF 3 D SHAPED PRECAST COMPONENTS
}

\author{
Thomas Bock \\ Prof. Dr.-Ing./ Univ. Tokio \\ Chair for Building Realization and -informatics \\ TU Munich, Arcisstrasse 21, D 80333 Germany \\ www.bri.ar.tum.de
}

\begin{abstract}
Multifunctional robotic production cells were first applied in the prefabrication of concrete floor panels and later for wall and roof panels. The next step was to design and produce not only flat panels but also 3 dimensionally curved panels, in which each panel had 3 dimensionally varying curvatures. The technological progress of robotics allows recently the digital design and production of highly customized facades.
\end{abstract}

\section{KEYWORDS}

Digital architecture, digital design, digital production, automation, robotics, industrialization, customization

\section{DIGITAL CAPACITY PLANNING}

In the 80artuar is of last century new ways of producing precast concrete or timber elements efficiently and at a high standard had been introduced using CNC technologies.

The possibilities offered by the machines and production technologies which are currently available were to be fully exploited. It was recognised that the combination of a well trained staff and sensible machine technology would bode well for the success of an industrial company in the future.
In order to achieve appropriate return on investment the production of the plant should achieve a rate of 500 square meter panel area per hour.

\subsection{Dimensions of the 2-D elements}

The main purpose of the plant is to produce facade elements for industrial and commercial buildings. The elements are up to $13 \mathrm{~m}$ long, $2.5 \mathrm{~m}$ wide and, in most cases, 140, 160, or $200 \mathrm{~mm}$ thick. The surfaces can be given a coloured or grey face-concrete structure, exposed aggregate, or anything else. The wall elements are provided with core insulation consisting of polystyrene insulation blocks. The sides are smooth or can also be provided with tongue and groove. All the edges are chamfered. 


\subsection{Robotic formwork system}

One important component of the efficient circulation system is a complex and very flexible, robotcompatible, solid-wall formwork system. The formwork profiles were made using a welding robot with the highest precision. Each compact formwork profile is fitted with two adjustable permanent magnets to stop it from shifting during the manufacturing process on the circulation plant. The formworks can be removed from the pallet later without much effort by manually deactivating the magnets (Figure 1).

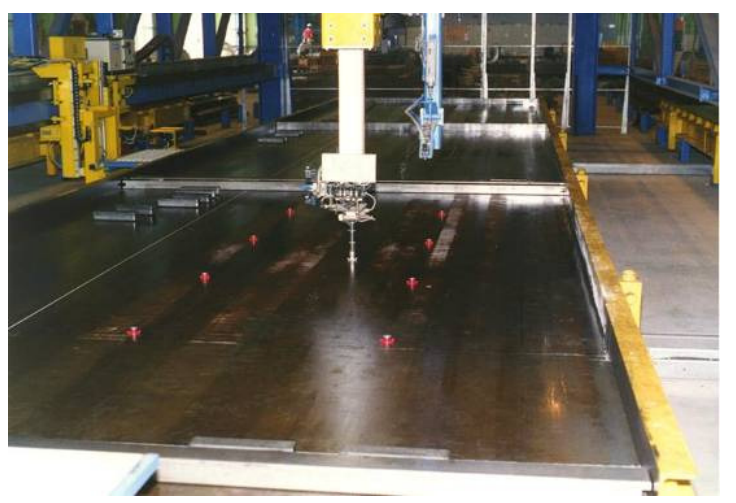

Figure 1. Insert Robot - Setting of a screw socket [1]

The variety of formwork types which differ in length, height and shape was deliberately reduced to a minimum in order to achieve economy of scale effects. With the existing formworks, any length, height, or thickness of wall can be produced within the framework of the available pallet size. The formworks can be used on both sides and correspondingly both as cross formwork or longitudinal formwork depending on the dimensions of the solid wall which is being produced.

Each pallet is provided with fixed-edge formwork on one side, which can be made higher if necessary with edge formwork, depending on the wall thickness which is being produced. The two basic edge formwork heights $140 \mathrm{~mm}(80 \%$ of the precast concrete elements) and $160 \mathrm{~mm}$ can be increased to $160 \mathrm{~mm}$ or $200 \mathrm{~mm}$ accordingly. The fixed-edge formworks are bolted to the pallets but can be removed and replaced whenever this is necessary. This also ensures that the circulation plant can be quickly and easily adjusted in relation to the product thickness or even the shape according to the changing market requirements in the future. The increased height of edge formwork is supplemented or removed on a manual formwork station. Most of the solid walls have a wall height of $2 \mathrm{~m}$ or $2.5 \mathrm{~m}$ and the lengths and quantity of the cross formworks have been selected accordingly. Other cross formwork lengths are $1 \mathrm{~m}$ and $1.5 \mathrm{~m}$. With walls of intermediate height, a telescopic metal sheet is inserted between the cross formwork and the longitudinal formwork which is fixed with a magnet box and XSmart support angles.

This system provides unlimited flexibility for the formwork concept.

\subsection{Digital production of 2-D elements}

The length of the plant altogether is approximately $130 \mathrm{~m}$ and the individual pallets are $14 \mathrm{~m}$ long and $2.78 \mathrm{~m}$ wide. With a pallet loading of $20 \mathrm{~m}^{2}$ and 10 pallets per hour, approximately $350,000 \mathrm{~m}^{2}$ facade elements are produced on average per year. The pallet circulation plant consists of 18 workstations and 104 places in the rack system. The rack itself is insulated and provides the optimum conditions for fast and careful curing of the high-quality facade elements. Each rack compartment can be accessed via a segment gate system. Every time an element is loaded or retrieved, only one of the 104 narrow segments is opened so that the prevailing conditions in the rack for optimum curing are hardly affected. The rack-operating unit moves along the floor (Figure 2).

The track lies on the rack supports of the first row. All travel and lifting movements are step less so the speed of lifting the pallets when empty is higher than the speed of lifting them when loaded. This saves energy and makes optimum use of the motor power. The pallets travel along and across on roller blocks, friction wheels and transverse elevating truck platforms as standard. Anything up to $100 \mathrm{~kg}$ payload and are made available by the magazine robot, are taken from the transport belt and placed directly on the pallet and then the integrated magnets are activated. The robot is also fitted with a plotting device which marks out the fittings, doors and windows (Figure 3). 


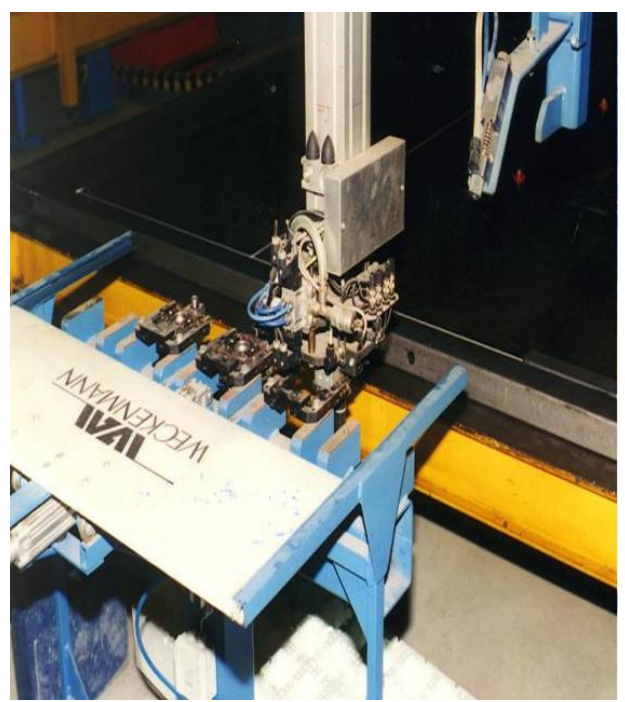

Figure 2. Insert Robot - Exchange of the gripper [1]

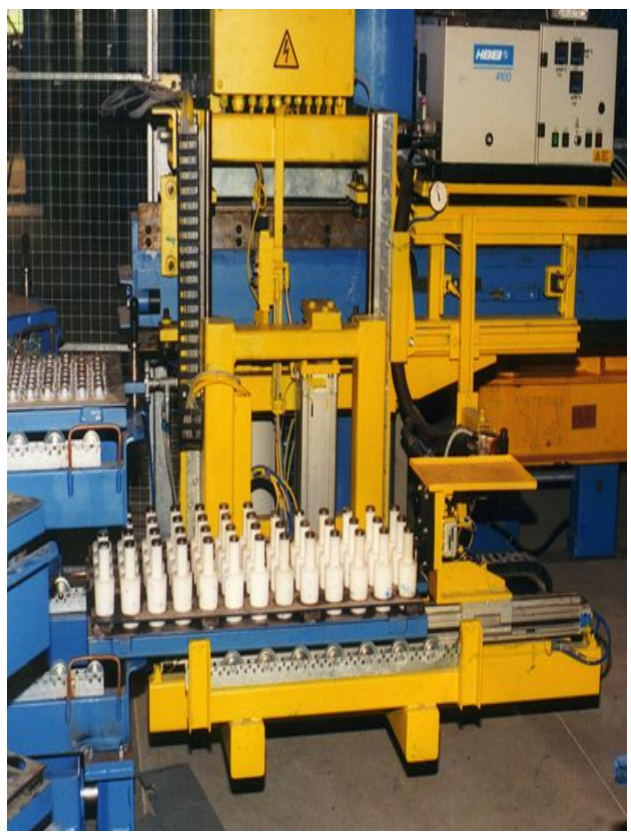

Figure 3. Tray with sparing on the shuttle [1]

On the two subsequent manual workstations, the formwork is extended, fittings placed and the window and door formwork placed on the pallet by hand. The handling crane is made available to the workers for this purpose (Figures 4, 5, 6).

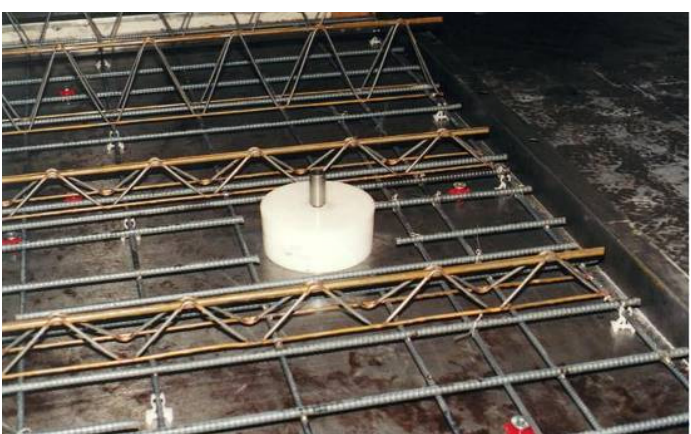

Figure 4. Round sparing, reusable [1]

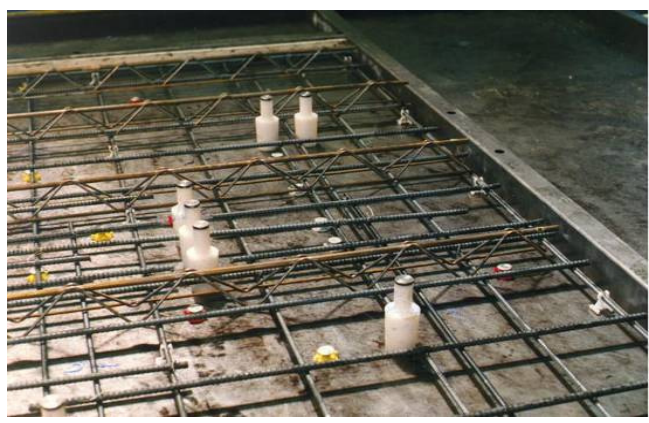

Figure 5. Screw sockets and sparings [1]

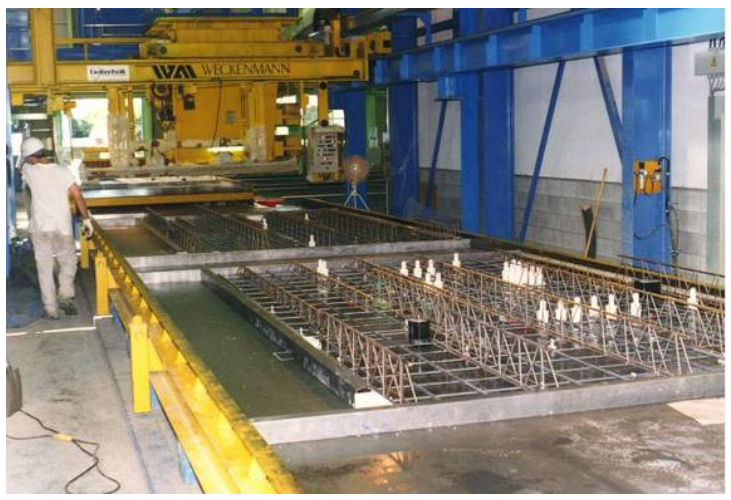

Figure 6. Pallet in concreting station [1]

On the two subsequent pallet stations, the premanufactured reinforcement is placed manually, also using handling cranes. This may consist both of individual rods and reinforcement mats. U07 is a buffer station on which the remaining reinforcement can be placed. 
At cycle station U08, the first layer of fresh concrete is introduced. While the concrete distributor collects the next mix from the mobile intermediate silo, the pallet switches to Station U13. The first layer is preliminary-compacted by the vibratory compactor (noise emission less than $70 \mathrm{~dB}(\mathrm{~A})$ ), the second half of the fresh concrete is introduced and then the freshly concreted elements are given their final compaction.

Above the pallet station U14, there is a mobile device for screeding the concrete by means of a vibrating beam.

The cycle stations U15 and U16 are used for the final inspection before the pallets are stored in the rack system or they are used as buffer stations.

The rack operating unit (U18) takes the pallets with the freshly produced façade elements and transports them to a free compartment in the rack system. The heat of hydration produced and the moisture conditions create the optimum curing conditions for the elements

\subsection{Digital control concept}

The production planning system operates with a $\mathrm{CAD}$ system and the entire production is controlled by a CAM system, a master computer which has been developed especially for the precast concrete industry. This forms the link between the CAD system, the operator and machine control systems.

The following modules of the CAM system guarantee efficient production:

Pallet allocation

- CAM receives the elements to be produced from the CAD system, allocates the pallets automatically and defines the optimum production sequence.

Pallet transport

- All pallet movements and dwell times in the circulation system and the curing chamber are co-ordinated according to the product.

$\mathrm{NC}$-data generation

- CAM supplies the formwork robot with optimised NC data.

\subsection{Digital production management}

The operator is constantly kept informed of the following via a graphics display of the system: -pallet location in the plant/ malfunction/ element delivery time / Information management. Documents for production and the construction site, statistical data for the management and feedbacks for the PPS system etc are output. The machine control systems of the circulation system and formwork robot are based on the Siemens S7 and the highest priority has been given to providing control hardware with maximum reliability. As far as possible, the control software consists of standard modules which are already in use on a large number of plants. For service purposes, both the master computer and the plant controls can be looked after from a distance via a modem.

An uninterruptable power supply (UPS) guarantees continuous operation of the computers if there is a power failure. The production manager can see all the information he needs at a glance on the control stand via the plant display. The state of the plant, the respective production times at each pallet station, disruptions and fault messages are collected centrally, evaluated and passed on. Thus bottlenecks can be determined and the plant continuously optimised and adjusted to requirements as they change. The Intranet is first connected to the production facility office and from there to the control station via a router. The data flow in both directions on-line provides a rapid supply of production data and allows the production state and production values to be called up from the control panel by the head office directly.

\section{HYBRID SITE AUTOMATION}

The first prototypes for automated high-rise construction sites were put into operation in 1990 and 1991 by Shimizu after five years in development and a financial outlay of almost 16 million euros. Since then, 20 automated high-rise sites have been operated by different companies (Taisei, Takenaka, Kajima, Maeda, Kumagai).

A hybrid high-rise construction site is understood as the semi-automated storage, transport and assembly equipment and/or robots used to erect a building 
almost completely automatically. It is the attempt to improve the sequencing of construction processes and construction site management by using real-time computerized control systems. This includes an unbroken flow of information from planning and designing the building through programming the robots with this data to using computers to control and monitor building operations on site.

After the foundations have been laid, the production equipment, on which the steel construction has been installed with assembly and transport robots, is covered completely with a roof of plastic film. Depending on the system, this takes from three to six weeks. Then the robots go into action. Two steel and ten concrete plants supply parts in ten-minute cycles on a just-in-time basis. This approach to supplying is not necessarily part of the system, but is due more to the lack of space around building sites in large Japanese cities. The prefabricated parts are checked and then placed in specific depots at the foot of the building or in the building itself to be available to the robots (Figure 7).

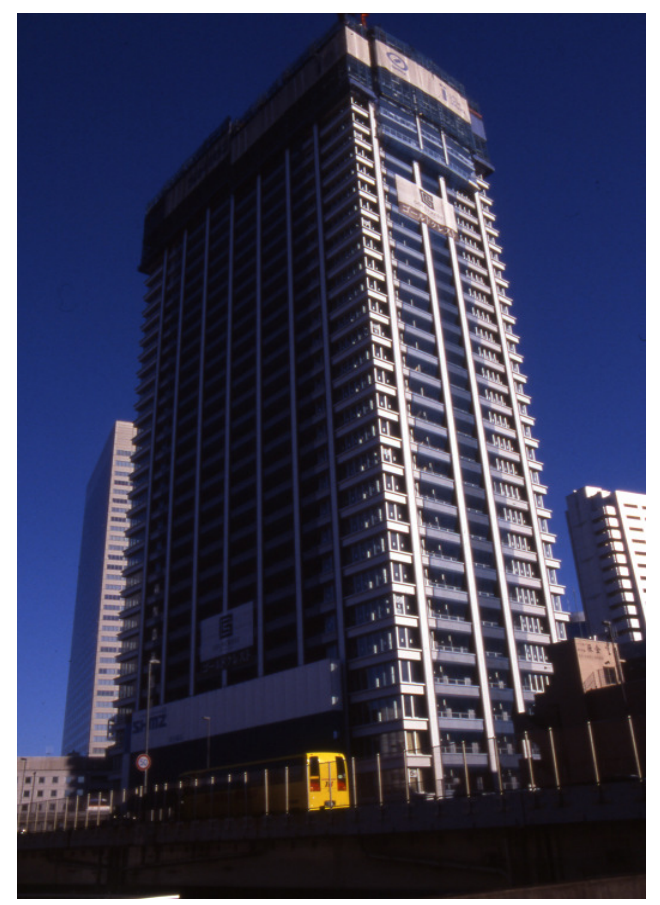

Figure 7. Hybrid Construction System, 2007 [2]
Once a story has been finished, the whole support structure which rests on four columns is pushed upwards by 12 hydraulic presses to the next story. Three 132 ton presses in each pillar are required to achieve this in 1.5 hours. Fully extended, the support structure is 25 meters high; retracted it measures 4.5 meters. Once everything has been moved up, work starts on the next story. By fitting out the topmost story of the high-rise as the roof at the beginning of the building process, the site is closed off in all directions, considerably reducing the effect of the weather and any damage it might cause.

This system reduces labor requirements by around $30 \%$. Future projects are expected to achieve a labor saving of around $50 \%$. The building consists of a remarkably high proportion of prefabricated parts. Once the foundations have been laid, the remaining construction procedure can be described as a matter of configuring transport and geometry. All the elements are prefabricated; only some of the fitting, joint insulation and other minor works need to be carried out by hand. Problems with the construction arise less from the timing of deliveries of materials or from the choice of processes and/or machines but more from the need for accurate planning, from programming the robots or from the just-in-time supply of parts.

\section{DIGITAL DESIGN AND PRODUCTION OF 3 D ELEMENTS}

As an example of $3 \mathrm{D}$ very complex shaped and curved components, I got involved in project of house B of „Neuer Zollhof" by Frank O. Gehry in Duesseldorf (Figure 8).

The total construction time of this project was three years (1996-1999). The complex consists out of three buildings called House A, House B and House C.

The perimeter walls of House A are plane and $4^{\circ}$ to $6.5^{\circ}$ vertically inclined prefabricated elements. Those elements proved to be the cheapest solution for these extraordinary shapes.

The geometry of the pieces was described digitally and then built in three dimensions. The 2D drawings for the formwork plans were automatically generated by CATIA-CAD, software for airplane design. 
According to those drawings the plant produced the pieces. Almost every part is unique (Figure 9).

The pre-cast elements had a thickness of $25 \mathrm{~cm}$ and were approximately $6 \mathrm{~m}$ high, $4 \mathrm{~m}$ wide by a weight of $9 \mathrm{t}$.

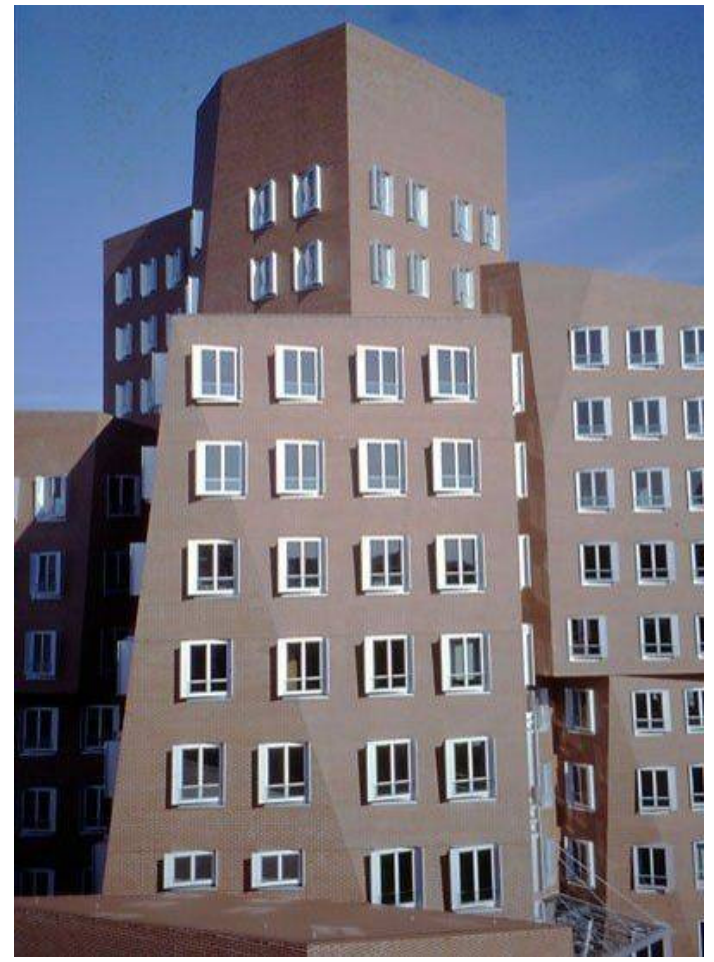

Figure 8. House A with clinker façade [3]

All parts were assembled by crane. In a few exceptions a lorry mounted telescopic crane was needed (Figure 10).

The clinker facade required extensive details and good craft skills.

House B consists out of 355 prefabricated nonstructural perimeter wall-elements which are carried by cast-in-place concrete ceilings (Figure 11).

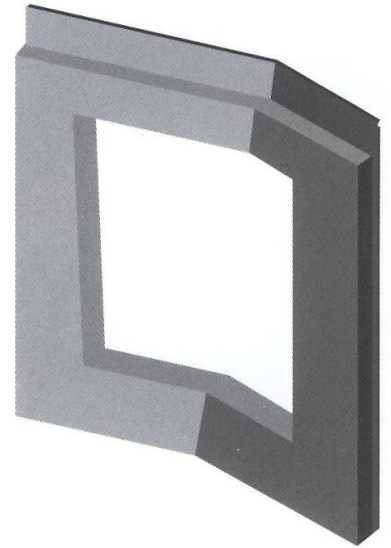

Figure 9. 3D-image of prefabricated element of House A [3]

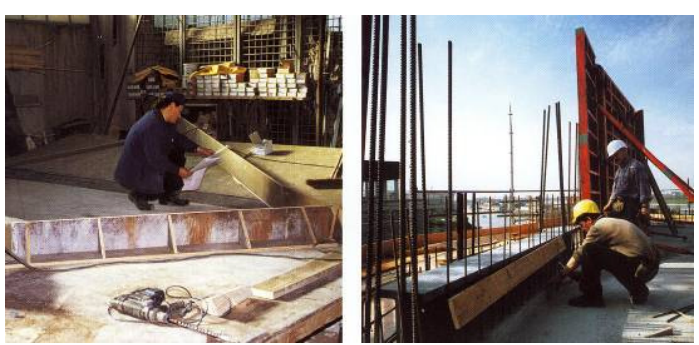

Figure 10. Conventional moulding on site for house A [3]

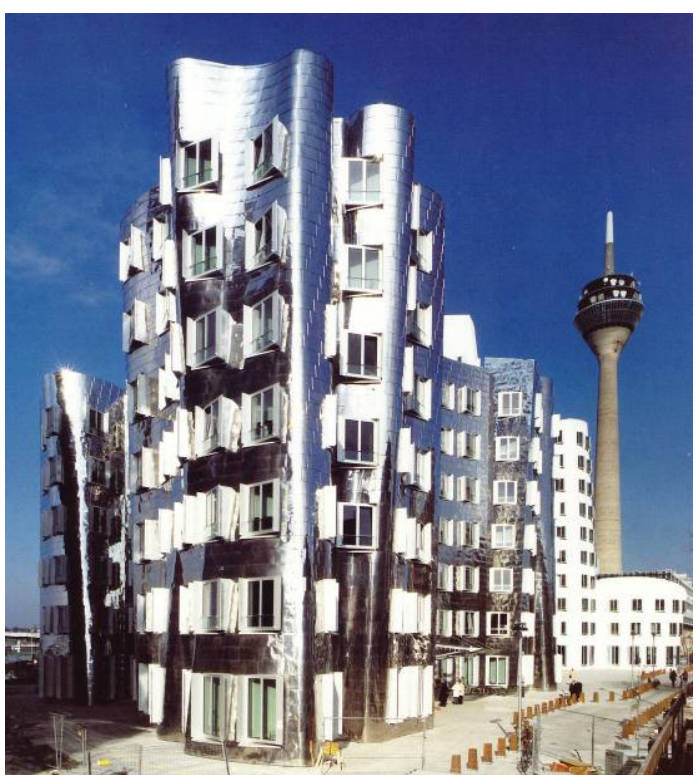

Figure 11. House B stainless steel facade [3] 
The new method, which was patented, allowed a widely computer-aided production of the prefabricated elements. With CATIA the complex geometry of the building was cut into single "floor slices" and then converted so that the data could be used in AutoCAD for further architectural planning. Each floor was split into single elements according to assembly and structural needs and then the data were reconverted into CATIA in order to be delivered to a milling shop (Figure 12).

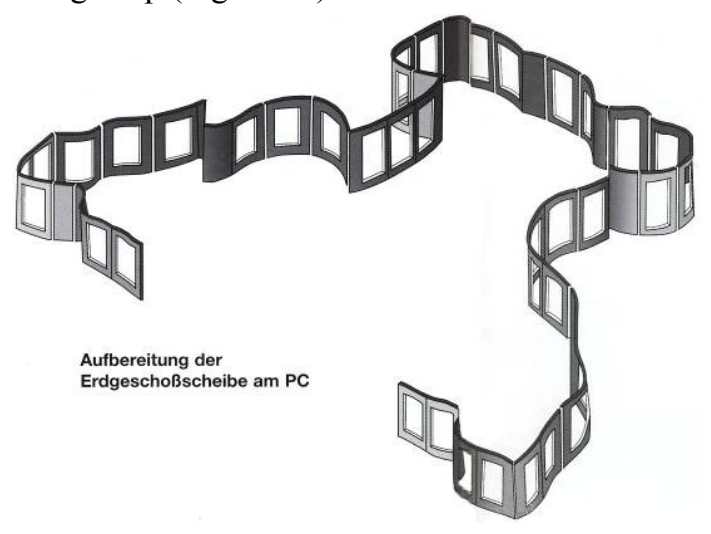

Figure 12. First floor "slice" in 3D

There the polystyrene-formworks were produced by CNC-milling machines (Figures 13-14).

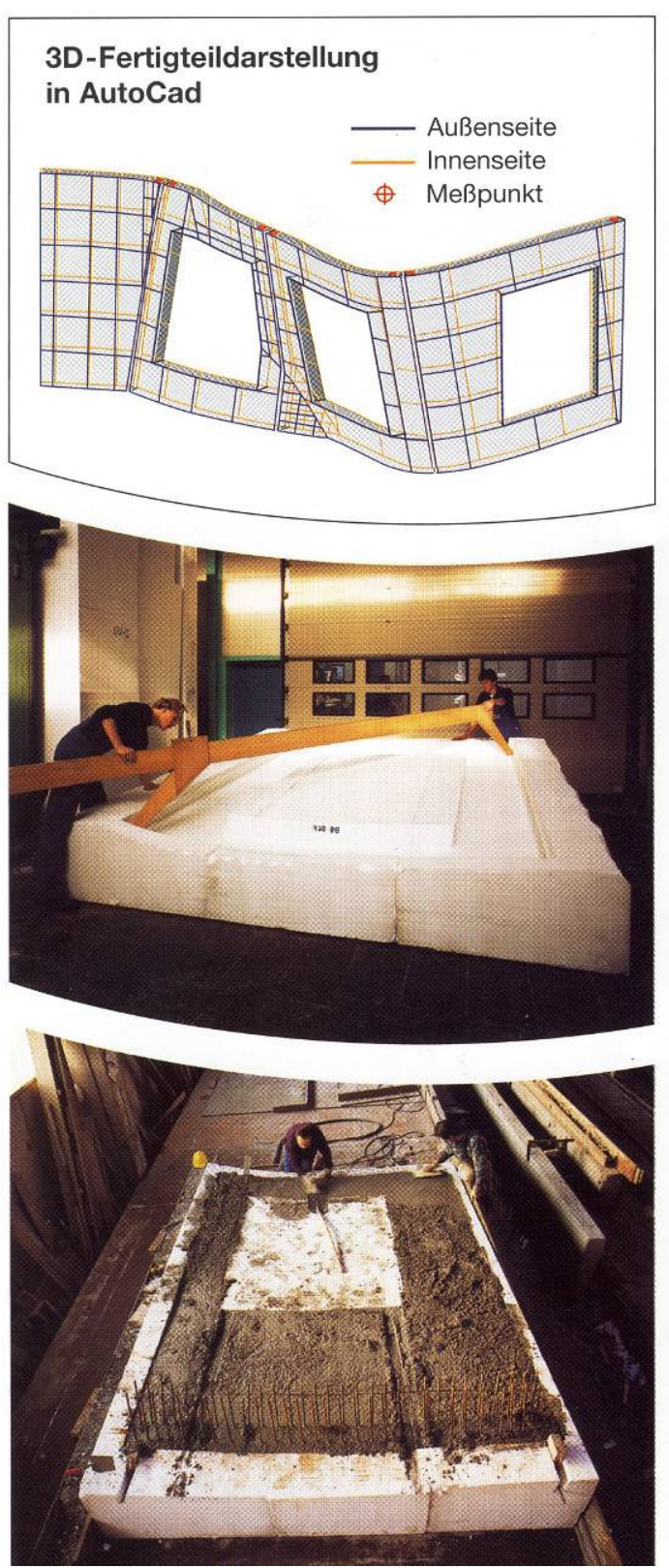

Figure 13. CNC-milling machine producing a polystyrene formwork [3] 

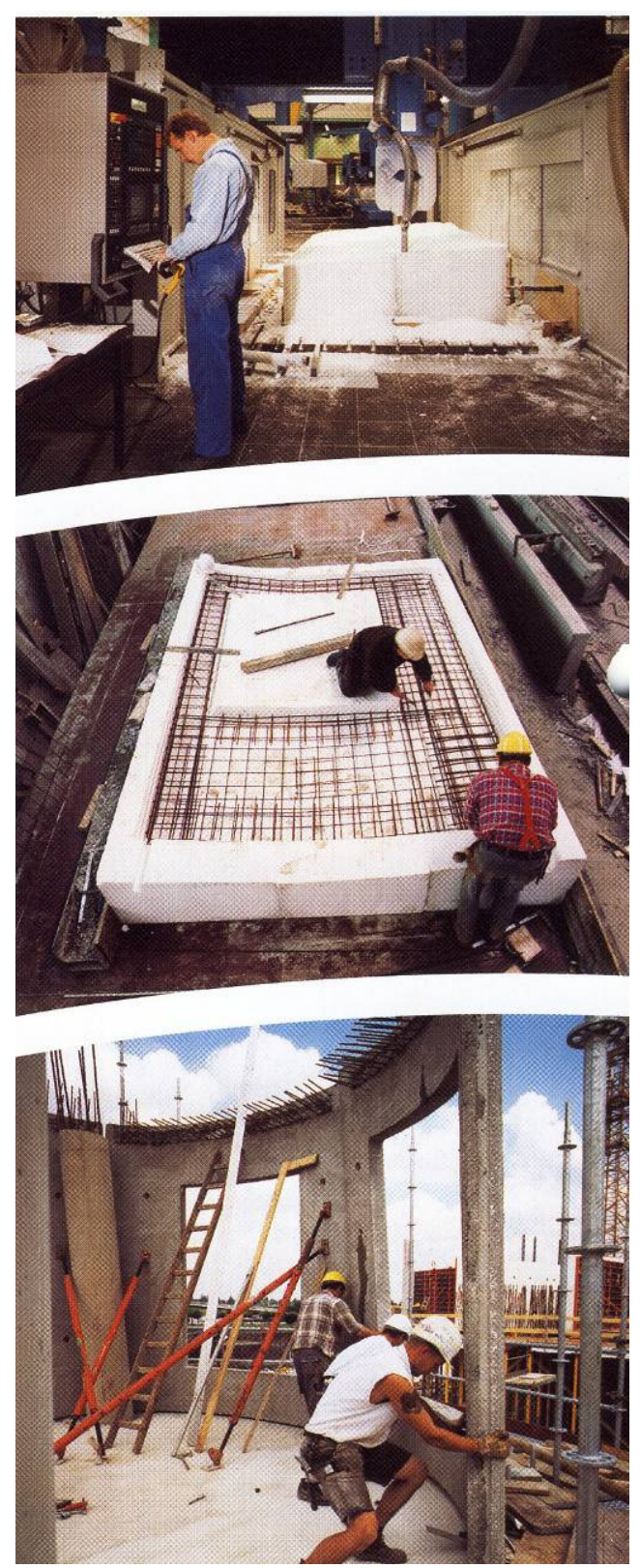

Figure 14. CNC-milling machine producing a polystyrene formwork [3]

With the formworks the $18 \mathrm{~cm}$ thick precastconcrete elements were manufactured and then delivered to the construction site "just-in-time". (Figure 15).

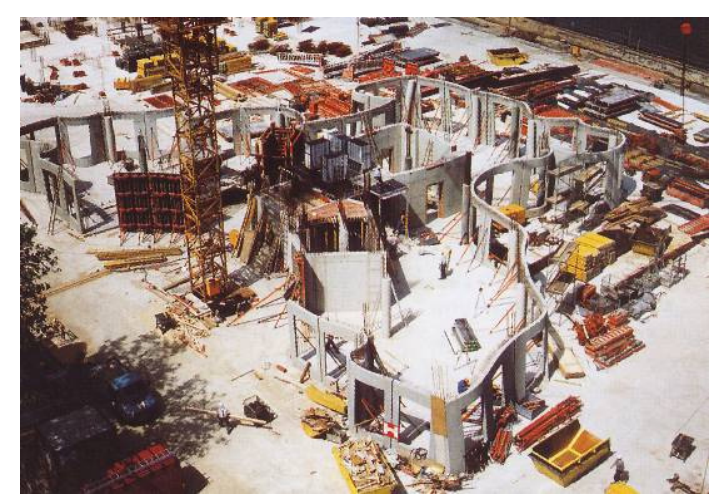

Figure 15. First floor: just-in-time assembly of the elements [3]

In comparison to House B the perimeter walls are made of masonry due to reduced curvature.

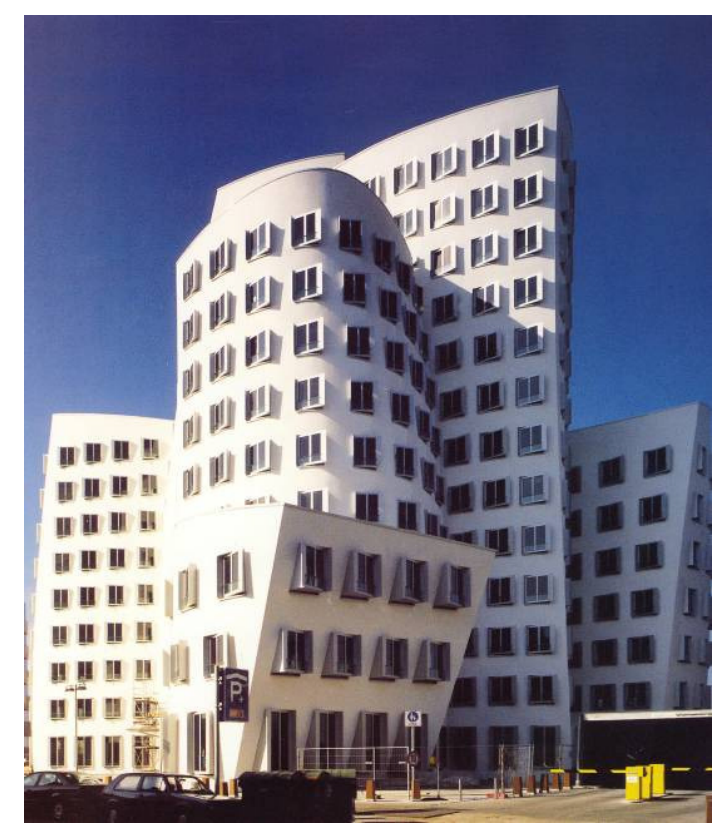

Figure 16. House C white plaster [3]

The freeform inclined surface of the cast-in-place walls of House $\mathrm{C}$ were built in a similar way as the prefabricated elements of House B (Figure 16). The concrete parts were digitally generated so that the $\mathrm{CNC}$-milled and form defining polystyrene pieces fit in between the plane formworks (Figure 17). 
The milling process for the polystyrene-formwork was similar to the one in House B. On site the pieces were integrated into the regular formwork. The walls are all cast-in-place concrete.
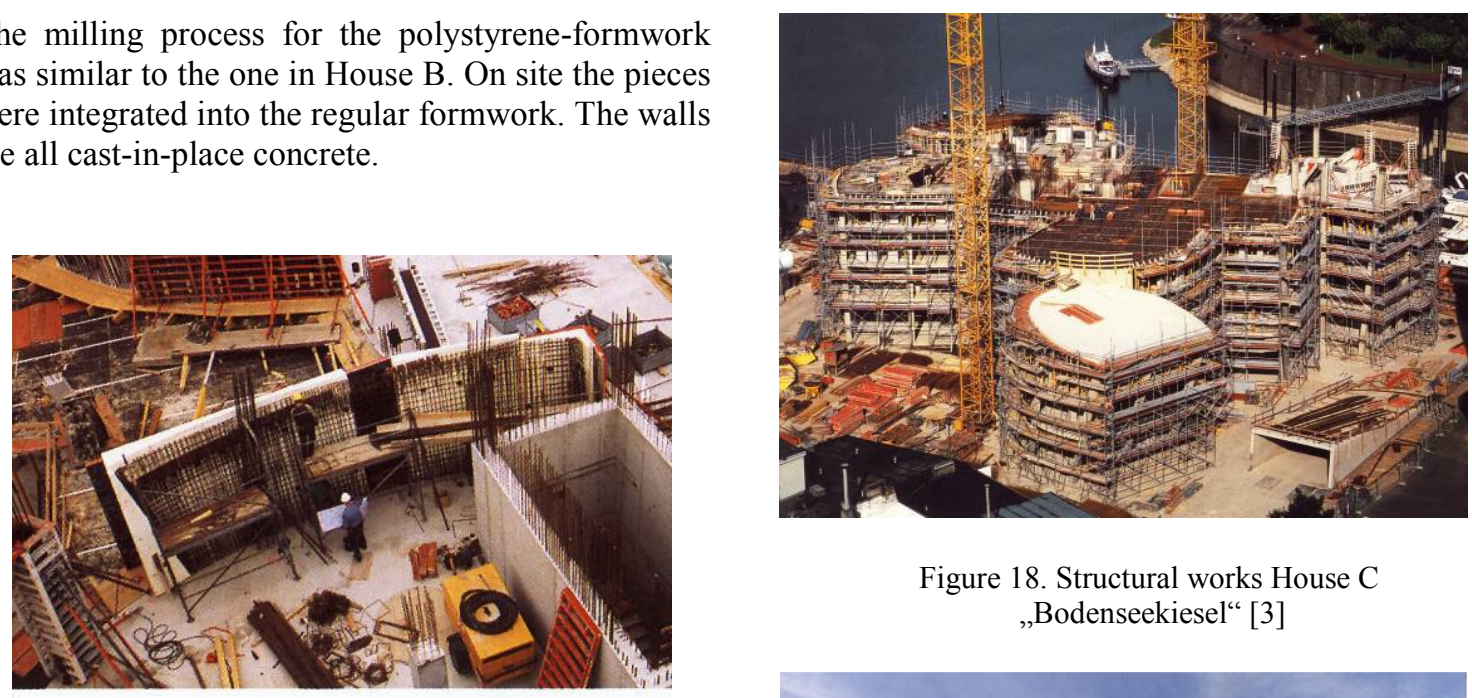

Figure 18. Structural works House C „Bodenseekiesel“ [3]
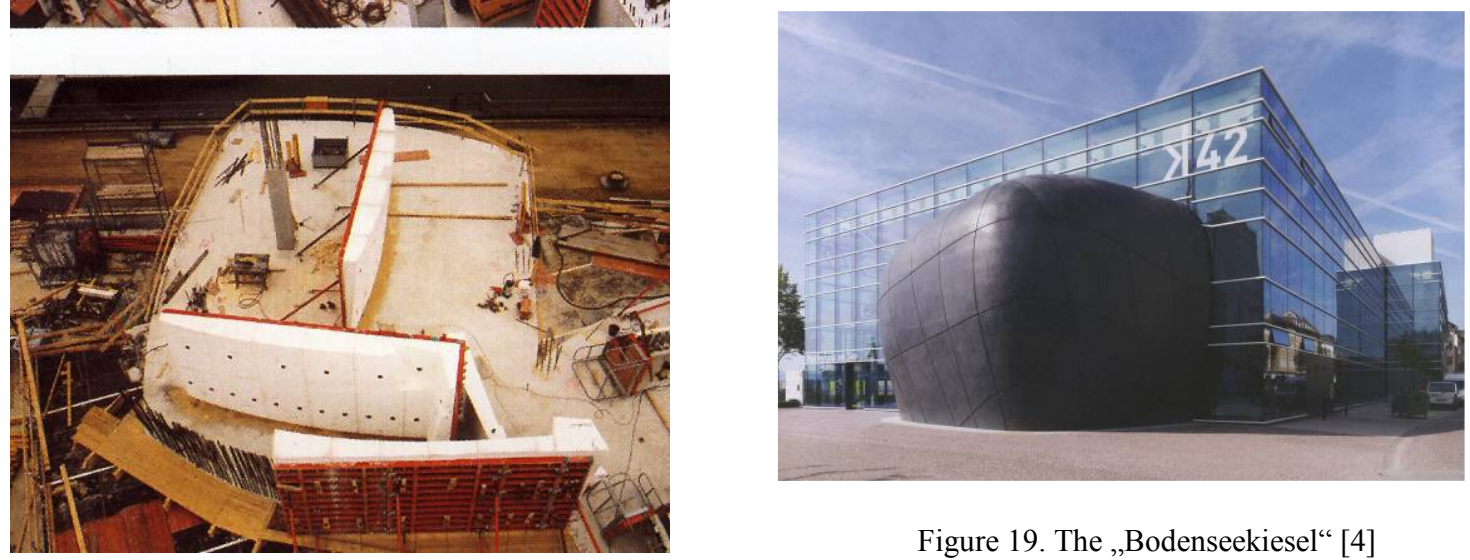

Figure 19. The „Bodenseekiesel“ [4]

Figure 17. The reinforcement is placed in front of a formwork element, prepared wall formwork [3]

The organic shaped convention space, which is has a pebble as model, was developed in a highly complex and currently unique construction method. The unusual building with 3-dimensional bend walls is based on a wood-steel structure which is clad by 124 glassfiber-concrete facade elements with a maximum height of $5,30 \mathrm{~m}$ and a maximum width of $4 \mathrm{~m}$ by $25 \mathrm{~mm}$ thickness (Figures 18-20).

The facade elements out of thin, flexibel and at the same time stable glassfiber-concrete are fixed to a glued-laminated timber girder combined with a steelframe structure.

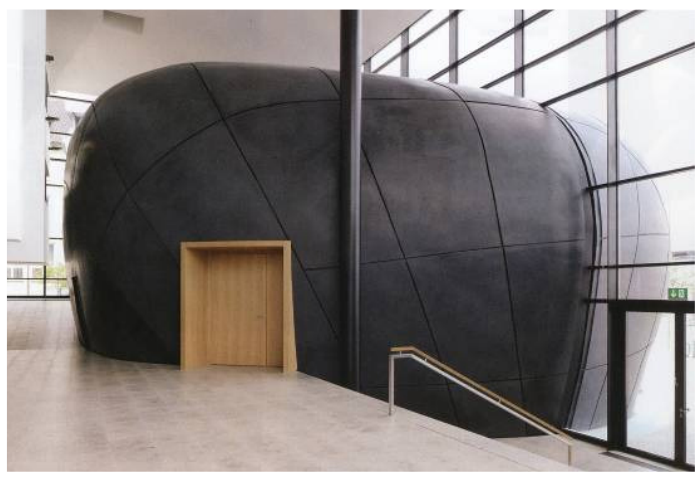

Figure 20. House within a House - the convention space by $2 / 3$ inside the mediahouse [4] 
To be able to manufacture the facade elements the specialists decided to build a Styrofoam model in 1:1 first. On the base of the digital model the heights and sections for the realization were calculated.
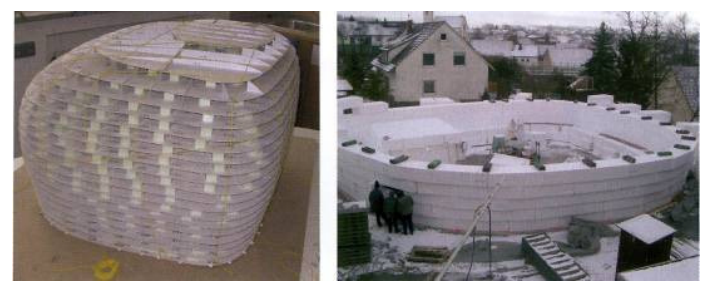

Figure 21. Model of the Styrofoam-igloo und the realization of the $1: 1$ prototype [5]

The production of the prefabricated glassfiberconcrete elements was a highly complex procedure. The styrofoam-igloo was digitally scanned and then split and cut into 124 pieces (Figures 21-25).

The single pieces became at the same time formworks for the manufacturing process.
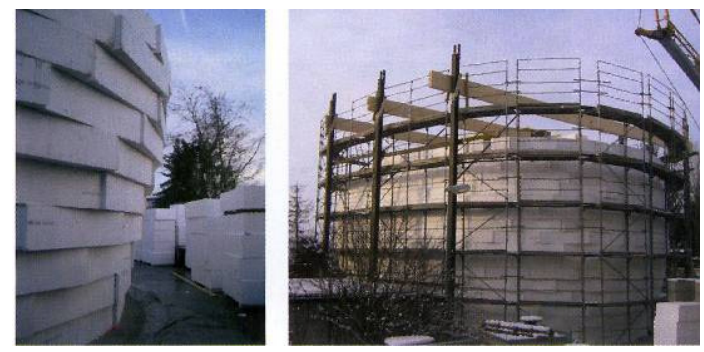

Figure 22. Prototype of the igloo [5]

The conventional realization with steelreinforcement would have been impossible. The $2,5 \mathrm{~cm}$ thick glassfiber-concrete and the unconventional method of the engineers made the realization possible.

Every facade element became unique. To ensure the same colour for each element the manufacturer needed to take special care of the sequencing of the mixture, the temperatures and the mixturing time in the machines and in the production facilities (Figure 26).
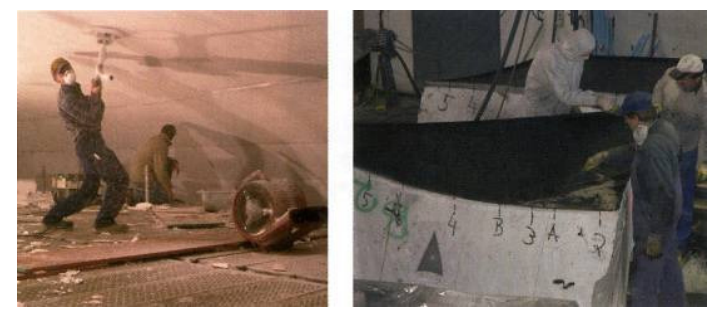

Figure 23. Modelling of the pebble-form in the igloo; production of the fiberglass-concrete elements [5]
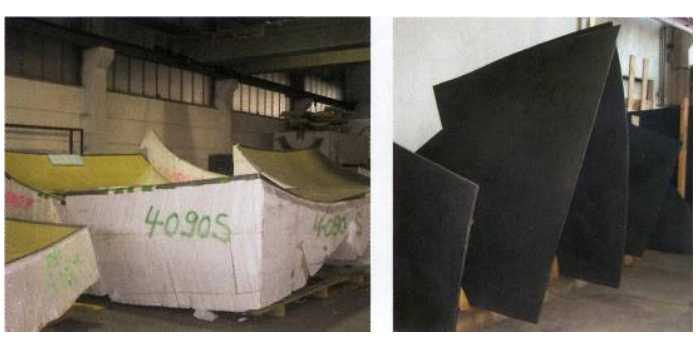

Figure 23. Production of the glassfiber-concrete elements [5]
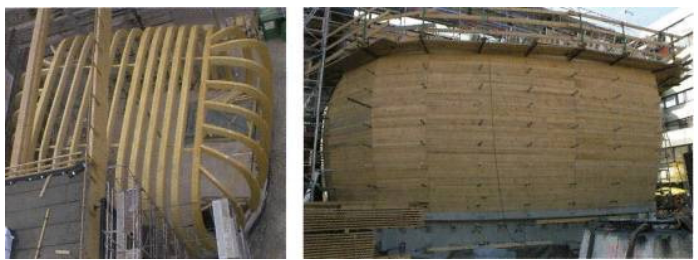

Figure 24. Assembly of the wood structure [5]
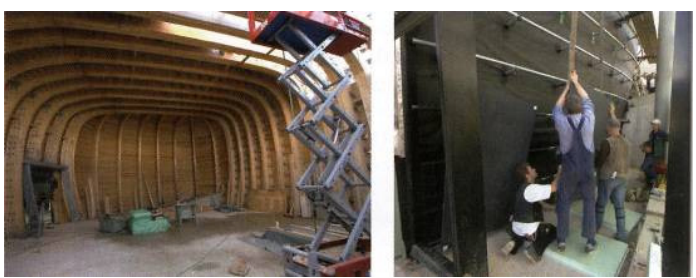

Figure 25. Inside of the wood structure and construction of the facade-elements [5] 

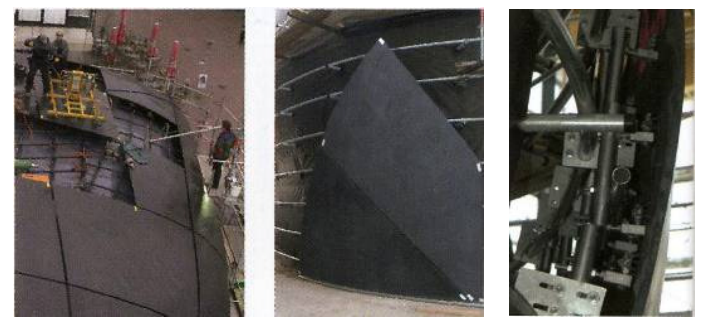

Figure 26. Construction of the facade elements connection detail facade - structure [5]

\section{CONCLUSION}

The research, development and application of digital technologies to architectural design and production offers new horizons in the industrialization of the construction industry during the last 3 decades. Only because of robotic technologies in prefabrication, on site construction and services, we will be able to realize one of kind component and building design at affordable construction costs and constant quality and ergonomic working conditions. Recent advances in $\mathrm{CNC}$ technologies enables us to design and produce highly individualized building elements of very complex geometries.

\section{REFERENCES}

[1] Pictures1-6, copyright, Herrmann Weckenmann, Germany

[2] Picture 7, copyright, Thomas Bock, TU Munich, Germany

[3] Pictures 8-18, copyright, Philipp Holzmann AG, Germany

[4] Pictures 19-20, copyright, Conne van d'Grachten, Germany

[5] Pictures 21-26, copyright, Schmidt Bauunternehmen and Rudolph Baustoffwerk, Germany 